\title{
Simple procedures to assess and compare the ecological niche of species
}

\author{
Grégory Beaugrand ${ }^{1, *}$, Pierre Helaouët ${ }^{1,2}$ \\ ${ }^{1}$ Centre National de la Recherche Scientifique (CNRS), UMR 8013 ELICO, Station Marine, BP 80, 62930 Wimereux, France \\ ${ }^{2}$ Sir Alister Hardy Foundation for Ocean Science, The Laboratory Citadel Hill, Plymouth PL1 2PB, UK
}

\begin{abstract}
Hutchinson's (1957; Cold Spring Harbour Symp Quant Biol 22:415-427) niche concept is being used increasingly in the context of global change, and is currently applied to many ecological issues including climate change, exotic species invasion and management of endangered species. For both the marine and terrestrial realms, there is a growing need to assess the breadth of the niches of individual species and to make comparisons among them to forecast the species' capabilities to adapt to global change. In this paper, we describe simple non-parametric multivariate procedures derived from a method originally used in climatology to (1) evaluate the breadth of the ecological niche of a species and (2) examine whether the niches are significantly separated. We first applied the statistical procedures to a simple fictive example of 3 species separated by 2 environmental factors in order to describe the technique. We then used it to quantify and compare the ecological niche of 2 key-structural marine zooplankton copepod species, Calanus finmarchicus and C. helgolandicus, in the northern part of the North Atlantic Ocean using 3 environmental factors. The test demonstrates that the niches of both species are significantly separated and that the coldwater species has a niche larger than that of its warmer-water congeneric species.
\end{abstract}

KEY WORDS: Ecological niche $\cdot$ Niche assessment $\cdot$ Statistical modeling $\cdot$ Macroecology

\section{INTRODUCTION}

Spatial distribution of a species is not stable in time and space (Rosenzweig 1995). It changes continually, being the result of the adjustment of the species' physiology and life cycle to both abiotic and biotic factors (Longhurst 1998). Chorology, the study of the spatial distribution of organisms and the factors involved in its control necessitates having a clear idea of the ecological niche of the species (Lacoste \& Salanon 2001). Among the different definitions of the ecological niche of a species that have been proposed (e.g. Grinnell 1917, Elton 1927), the one from Hutchinson (1957) has been the most influential. Hutchinson (1957) defined the ecological niche as a multidimensional hypervolume with the factors of the environment as the axes. Contrary to the definition proposed by Grinnell (1917), the niche is a property of a species, not a property of the environment (Harmon et al. 2005). The notion of
Hutchinson (1957) is simple and represents a rigorous way of assessing the niche of a species (Pulliam 2000).

Forecasting the spatial distribution of a species has become an important issue in conservation (Austin 2002, Elith et al. 2006). Assessing the ecological niche of a species is important in terms of managing endangered species (Sanchez-Cordero et al. 2005), predicting the responses of species to global climate change (Pearson 1994, Berry et al. 2002) or assessing the potential effects of invasion of non-native species (Jackson et al. 2001). Researchers are commonly interested in (1) quantifying the breadth of the niche and (2) knowing whether the ecological niches of 2 species are distinct (e.g. Stewart et al. 2003). For up to 3 environmental factors, niche comparison can be accomplished by a simple examination of scatterplots (i.e. abundance as a function of the environmental descriptors). However, this method can lead to misinterpretation and does not numerically quantify either the 
breadth of the niche of a species or the probability that the niches are separated. Austin et al. (2006) recently stressed that quantifying the niche breadths along gradients remained an unresolved scientific issue. We propose simple multivariate non-parametric procedures derived from a method originally used in climatology (Mielke et al. 1981) to (1) numerically assess species niche breadth and (2) evaluate whether the ecological niches are significantly distinct. First, we describe the technique using a simple fictive example of 3 species distinguished by 2 factors. Then, we apply the technique on 2 key structural marine zooplankton copepod species in the northern part of the North Atlantic Ocean.

\section{MATERIALS AND METHODS}

Study area and biological data. The study zone corresponds to the northern part of the North Atlantic Ocean and extends from $99.5^{\circ} \mathrm{W}$ to $19.5^{\circ} \mathrm{E}$ longitude and $29.5^{\circ} \mathrm{N}$ to $69.5^{\circ} \mathrm{N}$ latitude. Biological data were provided by the Continuous Plankton Recorder (CPR) survey; information describing this large-scale plankton monitoring programme can be found in Warner \& Hays (1994), Batten et al. (2003) and Reid et al. (2003). Data for the period from 1958 to 2002 were used in the present study (Fig. 1). We applied numerical procedures to assess and compare the ecological niches of 2 marine pelagic calanoid copepods, Calanus finmarchicus and C. helgolandicus. These calanoids are key structural species in subarctic (C. finmarchicus) and temperate shelf-edge ( $C$. helgolandicus) regions of the North Atlantic Ocean (e.g. Bonnet et al. 2005, Speirs et al. 2005).

Environmental data. Three environmental factors were used to assess the ecological niches of the 2 Calanus species. The spatial extent of the environmental data considered in the present study is shown in Fig. 1. Temperature was an essential factor because of its recognized influence on plankton (Reid \& Edwards 2001a, Beaugrand \& Reid 2003, Beaugrand et al. 2003). Temperature data were provided by the Comprehensive Ocean-Atmosphere Data Set (COADS; www.cdc. noaa.gov) (Woodruff et al. 1987). Salinity also constitutes an important factor for many species (Mauchline 1998). Salinity data were extracted from the 'World Ocean Atlas 2001' database (www.nodc.noaa.gov/ OC5/WOA01/pr_woa01.html). Bathymetry is a factor especially influential for distribution of $C$. helgolandicus, which is considered to be a pseudo-oceanic species (i.e. a species that can be found in oceanic and neritic waters, but is mostly abundant above the shelfedge, Beaugrand et al. 2002a). Bathymetry data came from the General Bathymetric Chart of the Oceans

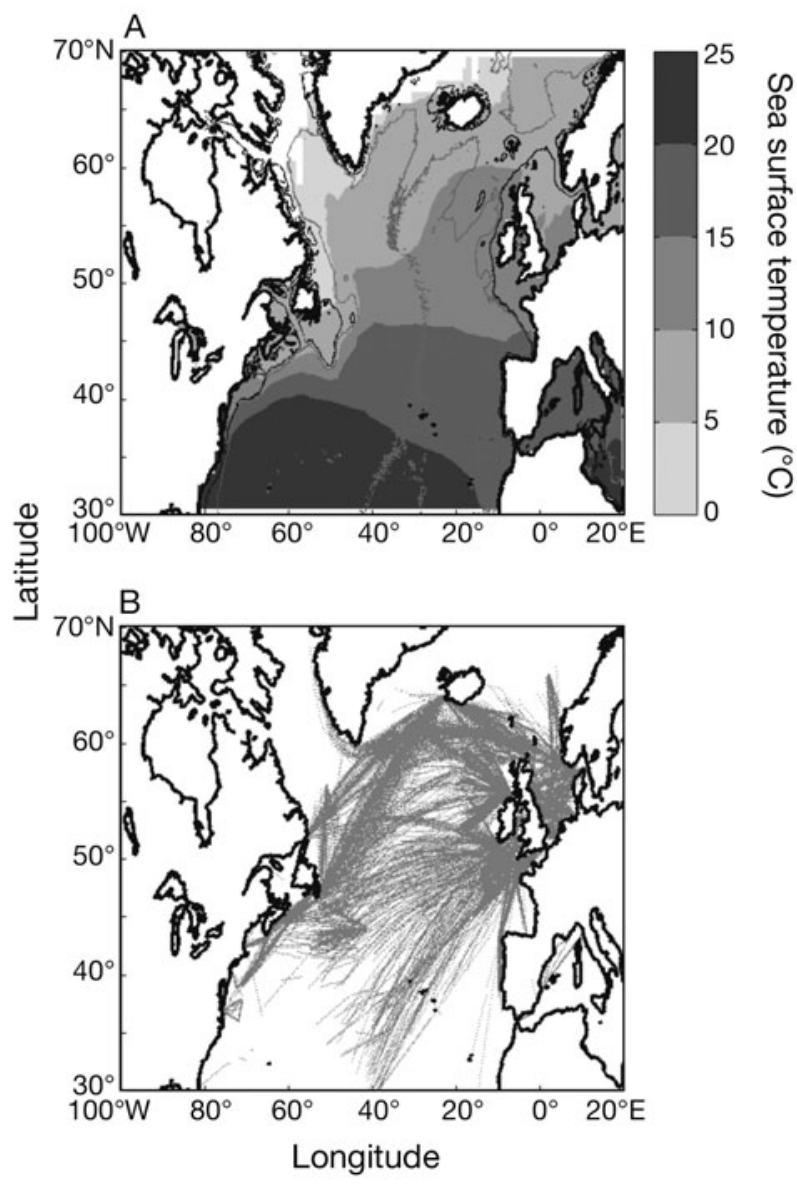

Fig. 1. (A) Spatial distribution of North Atlantic mean sea surface temperatures (grey scales), which reflect the spatial extent of environmental data used in this study. The isobaths of $200 \mathrm{~m}$ are also indicated. (B) Spatial distributions of the Continuous Plankton Recorder (CPR) samples for the period 1958-2002 (191028 CPR samples, grey dots)

(GEBCO; www.bodc.ac.uk/projects/international/gebco) database and an index of spatial variability in the bathymetry was calculated. In a geographical cell of $1^{\circ}$ latitude and $1^{\circ}$ longitude, both the average and standard deviation of bathymetry data were first calculated (225 data per geographical cell). Then, the coefficient of variation $(\mathrm{CV})$ was calculated as the percentage ratio of the standard deviation to the mean. A high variability in the bathymetry generally indicates continental slope regions (Fig. 2). The procedure is explained in more detail by Helaouët \& Beaugrand (2007).

Pre-processing of data. We calculated the mean abundance of both Calanus species for each category of (1) temperature (every $2^{\circ} \mathrm{C}$ between $-3^{\circ} \mathrm{C}$ to $35^{\circ} \mathrm{C}$ ), (2) salinity (every $0.5 \mathrm{psu}$ between $<30 \mathrm{psu}$ and $>39.5 \mathrm{psu}$ ) and (3) spatial variability of the bathymetry (every $10 \mathrm{~m}$ between $<-100 \mathrm{~m}$ and $0 \mathrm{~m}$ ). The class 


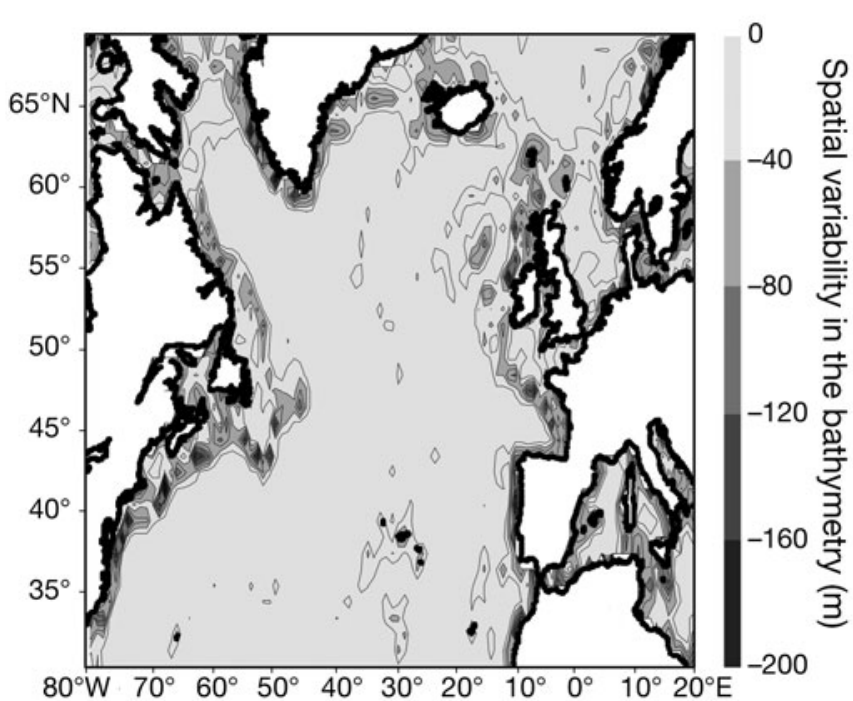

Fig. 2. Mapping of the index of spatial variability in the bathymetry (from Helaouët \& Beaugrand 2007)

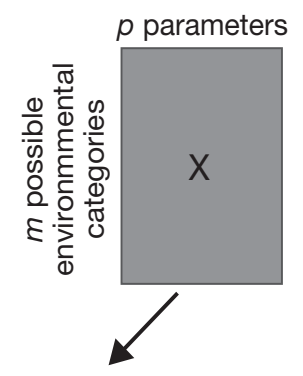

Species 1

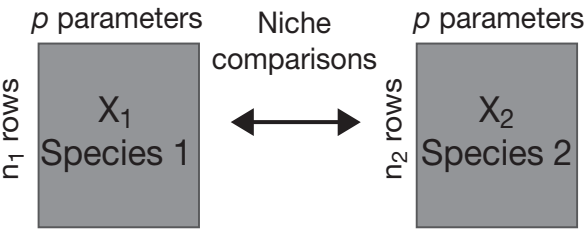

Case 2

all $x_{i}$ for $y_{i, 1}>$ first quartile for species 1

\section{Case 3}

all $\mathrm{x}_{\mathrm{i}}$ for $\mathrm{y}_{\mathrm{i}, 1}>$ median

for species 1

Case 4

all $x_{i}$ for $y_{i, 1}>$ third quartile for species 1

$p$ parameters

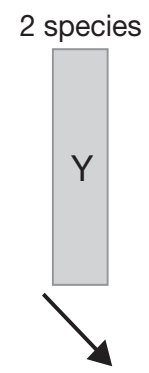

Species 2

$p$ parameters

\section{Case 1}

all $x_{i}$ for $y_{i, 2}>0$ for species 2

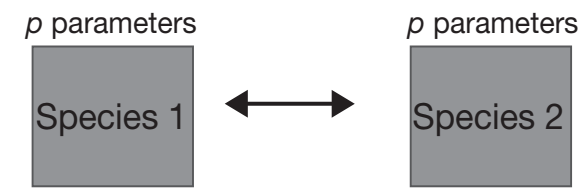

\section{$p$ parameters}
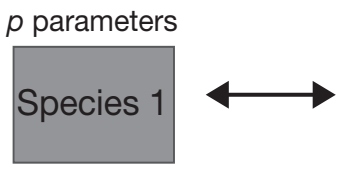

$p$ parameters

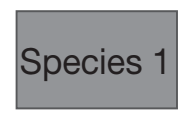

$p$ parameters
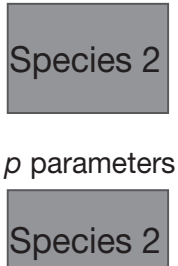

\section{Case 2}

all $x_{i}$ for $y_{i, 2}>$ first quartile for species 2

\section{Case 3}

all $x_{i}$ for $y_{i, 2}>$ median for species 2

Case 4 all $x_{i}$ for $y_{i, 2}>$ third quartile for species 2

intervals of each variable were selected on the basis of the examination of the frequency histogram of each environmental factor. This stage of the analysis was performed to represent visually the ecological niche of the species and then to apply the statistical procedures described as follows.

If $\mathrm{X}(m, p)$ is the matrix of $p$ environmental variables with the $m$ environmental categories, then each cell of $X$ represents the centre of the interval of an environmental variable (Fig. 3). If $C(p, 1)$ is the vector that contains the total number of category for each of the $p$ variables, then the number of rows $m$ in $\mathrm{X}$ is given by:

$$
m=\prod_{i=1}^{p} C_{i}
$$

The term $\mathrm{Y}(m, s)$ is the vector with $m$ abundance or presence/absence values corresponding to the $m$ environmental categories for the s species (Fig. 3). Missing data are often present in the matrix and correspond to an environmental category that was not sampled. The amount of missing data increases with the number of environmental variables (and therefore $m$ ). Only rows of X for which the species was detected (or belong to a certain category of abundance) are considered in the calculation. Therefore, the number of rows $n$ to be tested often varies between species (and $n \leq m$, Fig. 3).

The analyses were used based on occurrence data (all environmental data for which the abundance of species are $>0$, Case 1 , Fig. 3). For example, the data point for a temperature class centred on $10^{\circ} \mathrm{C}$, a salinity class of 34.75 psu and a spatial bathymetry variability class of -45 , was considered as abundance data for Calanus finmarchicus superior to 0 in these environmental inter-

Fig. 3. Origin of matrices tested in this study. Comparisons between species niches were performed for each case vals. This was not the situation for C. helgolandicus. The procedures were also used for abundance data > first quartile (Case 2), data $>$ median (Case 3), data $>$ third quartile (Case 4). The first quartile, the median and third quartile were assessed for each species from matrix Y. Reshaping and building of the matrices used in the analyses is illustrated in Fig. 3.

To assess and compare the ecological niche of 2 or more species, we propose a numerical analysis based on Multiple Reponse Permutation Procedures (MRPP, Mielke et al. 1981, Zimmerman et al. 1985). These procedures have been often applied with Split Moving Window Boundary ana- 
lysis (Webster 1973) to detect discontinuities in time series (Cornelius \& Reynolds 1991). For example, this method was applied to detect the substantial and rapid changes called regime shift (Reid \& Edwards 2001b) that occurred in North Sea plankton ecosystems (Beaugrand 2004b).

Assessment of the niche breadth. For each species and case (Fig. 3), the breadth of the ecological niche was assessed by calculating the Euclidean distance between all possible pairs of points. Each environmental variable was normalized to 1 prior to the calculation of Euclidean distances. The normalization is a special kind of scaling (Legendre \& Legendre 1998). Each element of the vector is divided by its length, using the Pythagorean formula. This transformation ensured that each variable had the same weight in the analysis.

The Euclidean distance $(d)$ between the rows $x_{j}$ and $x_{k}$ in the matrix $X$ (i.e. $n$ rows that represent the environmental categories in which the species is either $>0$, or $>$ first quartile, or $>$ median, or $>$ third quartile according to the different cases and $p$ columns representing the number of environmental variables) is calculated as follows:

$$
d\left(x_{j}, x_{k}\right)=\sqrt{\sum_{i=1}^{p}\left(x_{j, i}-X_{k, i}\right)^{2}}
$$

with $p$ being the number of environmental variables. The total number of Euclidean distances $(g)$ to be calculated for a species (and a case) is:

$$
g=n(n-1) / 2
$$

with $n$ being the number of rows in matrix X. Calculations are illustrated with a simple example (Table 1 , Fig. 4). No normalization was done in this example as it is fictive and we assume that the 2 variables have the same units. This is generally not the case with actual data and it is important to undertake a normalization procedure so as not to bias the results. In this example $n=3$ for Species 1. Three Euclidean distances should be calculated ( $g=3$, Table 1). Calculations give values of $d_{\left(\mathrm{x}_{1}, \mathrm{x}_{2}\right)}=2.236, d_{\left(\mathrm{x}_{1}, \mathrm{x}_{3}\right)}=2.000$ and $d_{\left(\mathrm{x}_{2}, \mathrm{x}_{3}\right)}=2.236$.

For each case and species, the mean Euclidean distance, $\varepsilon$, is then calculated to assess the breadth of the ecological niche as follows:

$$
\varepsilon=\frac{\sum_{i=1}^{g} d_{i}}{g}
$$

with $g$ being the total number of Euclidean distances calculated from X. In the example (Table 1, Fig. 4), $\varepsilon=(2.236+2.000+2.236) / 3=2.157$ for Species $1, \varepsilon=$ 2.452 for Species 2 and $\varepsilon=4.392$ for Species 3. Therefore, the breadth of the ecological niche (only based on 2 factors in this example) is greater for Species 3 than for Species 2 and Species 1 (Fig. 4).

\begin{tabular}{|c|c|c|c|c|c|}
\hline \multicolumn{2}{|c|}{$\begin{array}{l}- \text { Species } 1- \\
\text { Factor } 1 \text { Factor } 2\end{array}$} & \multicolumn{2}{|c|}{$\begin{array}{l}- \text { Species } 2- \\
\text { Factor } 1 \text { Factor } 2\end{array}$} & \multicolumn{2}{|c|}{$\begin{array}{l}- \text { Species } 3- \\
\text { Factor } 1 \text { Factor } 2\end{array}$} \\
\hline 1 & 1 & 4 & 4 & 1 & 2 \\
\hline 2 & 3 & 5 & 2 & 3 & 3 \\
\hline 3 & 1 & 5 & 5 & 6 & 5 \\
\hline - & - & 7 & 4 & 7 & 1 \\
\hline
\end{tabular}

Table 1. Fictive example showing the occurrence of 3 species according to 2 environmental variables. Data are untransformed

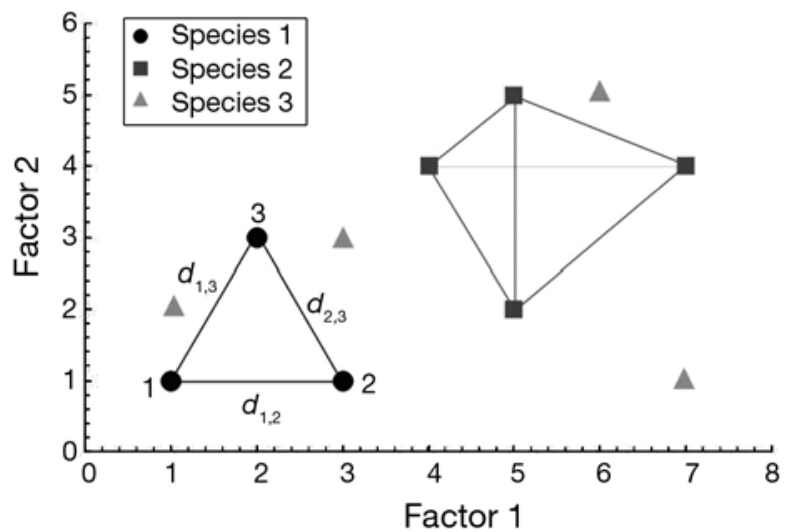

Fig. 4. Hypothetical ecological niche (sensu Hutchinson 1957) of 3 species in the space of 2 factors. All possible Euclidean distances $(d)$ are indicated for Species 1 and 2. Data are presented in Table 1

Test of niche separation. The following non-parametrical MRPP technique can then be applied to test whether the species have different ecological niches. The test statistic $\delta$ between Species 1 and 2 ( 2 species) and a given case is calculated as being the weighted mean of the values for $\varepsilon$ :

$$
\delta_{1,2}=\frac{g_{1} \varepsilon_{1}+g_{2} \varepsilon_{2}}{g_{1}+g_{2}}
$$

where $g_{1}$ and $g_{2}$ are the total number of Euclidean distances calculated for Species 1 (matrix $\mathrm{X}_{1}$ ) and Species 2 (matrix $\mathrm{X}_{2}$ ), respectively (see Fig. 2). The terms $\varepsilon_{1}$ and $\varepsilon_{2}$ are the mean Euclidean distances for Species 1 and 2, respectively.

The probability values of the MRPP statistics are determined by permutations (Zimmerman et al. 1985). For comparison of the ecological niche of 2 species (e.g. Species 1 and 2), the number of possible permutations, $\mathrm{PE}_{1,2}$, is:

$$
P E_{1,2}=\frac{\left(g_{1}+g_{2}\right) !}{g_{1} ! \times g_{2} !}
$$

In the example, $\mathrm{PE}_{1,2}=35$ permutations, $\mathrm{PE}_{1,3}=35$ permutations and $\mathrm{PE}_{2,3}=70$ permutations. The probability $p_{1,2}$ (e.g. Species 1 and 2 ) is calculated from the following formula: 


$$
\mathrm{p}_{1,2}=\frac{K_{\delta_{1,2}^{s}<\delta_{1,2}}}{P E_{1,2}}
$$

where $K_{\delta_{1,2}^{s}<\delta_{1,2}}$ is the number of recalculated or simulated $\delta_{1,2}$ (e.g. Species 1 and 2), called $\delta_{1,2}^{S}$, found to be inferior to the observed $\delta_{1,2}$ after permutation.

In the fictive example (Table 1, Fig. 4), the calculated values are $\delta_{1,2}=2.3260$ and $\mathrm{p}_{1,2}=0.0286$. Therefore, the ecological niche of Species 1 and 2 are significantly different. For Species 1 and $3, \delta_{1,3}=3.4342$ and $\mathrm{p}_{1,3}=$ 0.2857, and for Species 2 and $3, \delta_{2,3}=3.4221$ and $\mathrm{p}_{2,3}=$ 0.6286 , so that the niches do not significantly differ either between Species 1 and 3 or between Species 2 and 3 . The number of possible permutations is important to provide an idea of the robustness of the probability. In the example, it is relatively low. When the number of occurrence points begins to become moderately high, the test becomes rapidly robust. For example, for 2 species, one of which has 10 occurrences and the other 15, then 2.85 million permutations are possible. When the number of possible permutations is too high, it is not possible to do all calculations and Berry \& Mielke (1983) proposed using the Pearson Type III distribution instead. However in that case, only the Euclidean distance can be applied. We propose to use a finite number of permutations. A minimum number of 10000 permutations is generally recommended to stabilise the probability for tests based on random permutations such as Mantel's test (Jackson \& Somers 1989). This way of assessing the probability enables the use of any distance or similarity measures. This assumption works as long as there is no substantial difference in the number of occurrences (or abundance values $>$ first quartile, median or third quartiles), $n_{s}$ for each species.

\section{RESULTS}

The ecological niche for Calanus finmarchicus seems larger than that for C. helgolandicus (Fig. 5). As expected, C. finmarchicus has a temperature optimum lower than $C$. helgolandicus, but the former species is more eurythermal than the latter. Calanus helgolandicus is found at higher levels of salinity than is C. finmarchicus and in regions where spatial variability in the bathymetry is greater. Again, C. finmarchicus can tolerate higher variation in salinity than its congeneric species and is found in regions encompassing a greater diversity of bathymetry profiles (Fig. 5). The abundance patterns shown in Fig. 5 also suggest that the niches of both species are separated.

These findings are confirmed by the statistical procedures (Table 2). The procedure quantifies the breadth of the ecological niche of both Calanus species for sev-
Table 2. Calanus finmarchicus and C. helgolandicus. Results of the tests based on annual estimations of the abundance of both species in each category of temperature, salinity and variability of bathymetry. Case 1: all presence data, Case 2: abundance data $>1$ st quartile, Case 3: abundance data $>$ median, Case 4: abundance data > 3rd quartile. Niche breadth: breadth of the ecological niche of each species. p: probability that the niches of both species are different

\begin{tabular}{|c|c|c|c|}
\hline & \multicolumn{2}{|c|}{ Niche breadth } & \multirow{2}{*}{$\mathrm{p}$} \\
\hline & C. finmarchicus & C. helgolandicus & \\
\hline Case 1 & 6.6887 & 6.1066 & $<0.0001$ \\
\hline Case 2 & 6.4695 & 5.7971 & $<0.0001$ \\
\hline Case 3 & 6.2840 & 5.6667 & $<0.0001$ \\
\hline Case 4 & 6.1522 & 5.3492 & $<0.0001$ \\
\hline
\end{tabular}

eral levels of abundance. For all degrees of abundance, the breadth of the ecological niche of the subarctic species C. finmarchicus (e.g. value of 6.69 based on all presence data) is higher than the breadth of the niche of its congeneric temperate pseudo-oceanic species (e.g. value of 6.11 based on all presence data). When only high abundance data are considered (i.e. data > third quartile), the separation between both species is maximum. The procedure also demonstrates that both niches are significantly separated from each other (Table 2).

\section{DISCUSSION}

These results were expected as Calanus finmarchicus characterizes subarctic water while its congeneric species, C. helgolandicus, is more indicative of temperate waters (Beaugrand et al. 2002b, Beaugrand 2003, Bonnet et al. 2005, Helaouët \& Beaugrand 2007). Rapoport's rule suggests the existence of a latitudinal gradient in geographical range size and, therefore, an increased tolerance of high latitude species to environmental fluctuations (Stevens 1989). Our results conform to this ecogeographical pattern. The greater breadth of the niche of $C$. finmarchicus explains why the spatial distribution for this species is larger than for C. helgolandicus (Planque 1996, Beaugrand 2004a). Using the proposed procedures, quantification of the niche for species ranging from the equator to the pole could provide additional information on the validity of this long-debated pattern in ecology (Rohde et al. 1993, Colwell \& Hurtt 1994, Lyons \& Willig 1997, Sanders 2002).

Many methods have already been proposed to assess the ecological niche of species (for a review, see e.g. Guisan \& Zimmermann 2000, see also Hölzel 2003, Elith et al. 2006). Regression techniques are often applied to characterize the relationships between a 

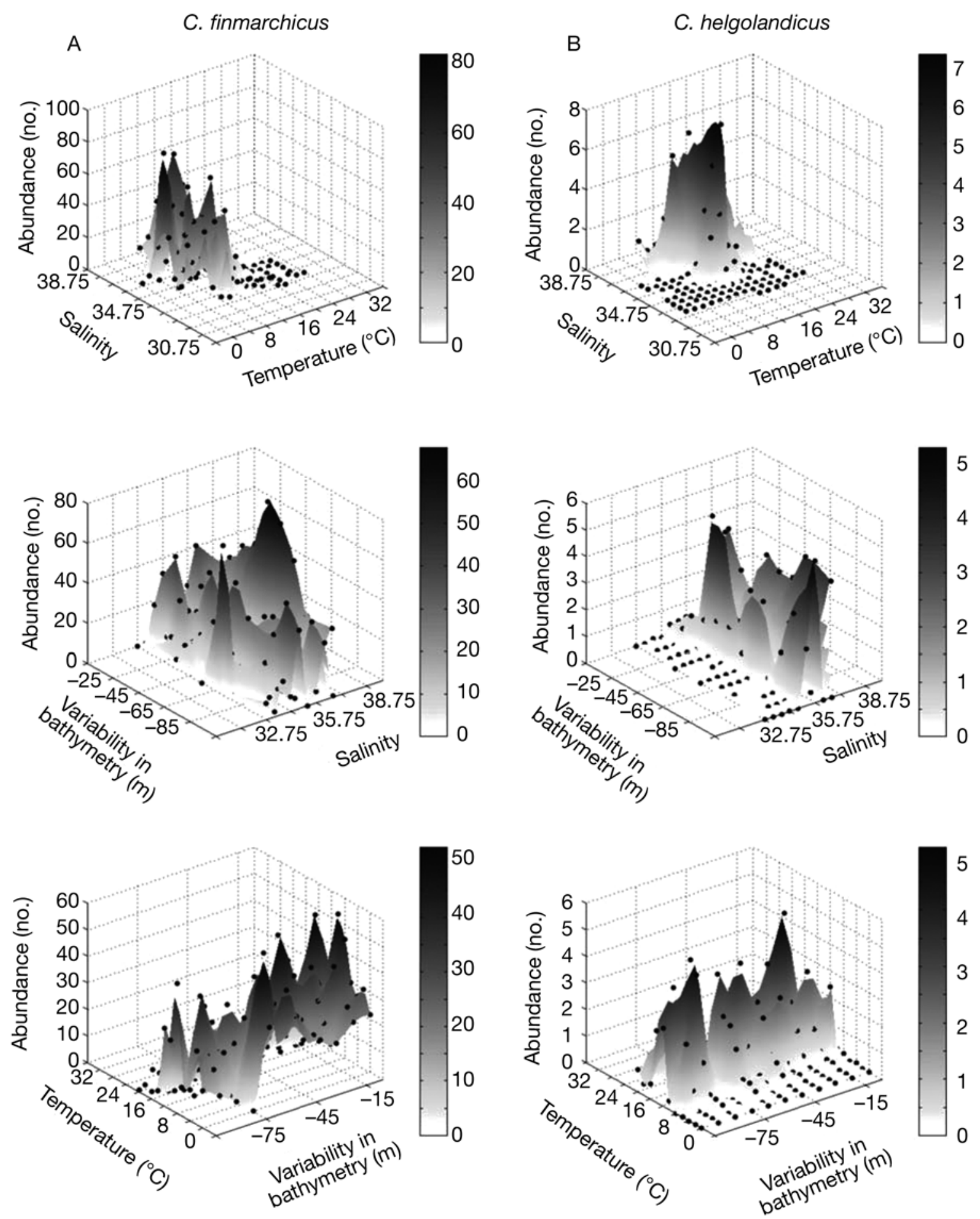

Fig. 5. Ecological niches of (A) Calanus finmarchicus and (B) C. helgolandicus based on temperature $\left({ }^{\circ} \mathrm{C}\right)$, salinity (psu) and variability in the bathymetry $(\mathrm{m})$. Black dots are measurements of the abundance of the species for a given environmental category and the shaded grey envelope indicates the ecological niche of the species, which was calculated by cubic polynomial interpolation

species and its environment (ter Braak \& Looman 1987). Regression techniques are selected according to the characteristics of the data (i.e. quantitative or categorical) and the number of explanatory variables to be included in the model. Generalised linear models (GLM, McCullagh \& Nelder 1983) and generalised additive models (GAM, Hastie \& Tibshirani 1990) have been most often used (Leathwick \& Austin 2001, Hee- 
gaard 2002). When more than 1 species is examined, canonical ordination techniques such as redundancy analysis (RDA) have been applied if the response of species to a change in the environment is assumed to be linear. When the response is expected to be unimodal, canonical correspondence analysis (CCA) can be computed (ter Braak 1987). Other methods such as artificial neural networks (ANN, Manel et al. 1999), regression trees and classification trees exist. Multivariate adaptive regression splines (MARS) combine regression trees with spline fitting and represent an interesting technique for modeling species distributions (Leathwick et al. 2006). Those methods, however, do not allow assessment and direct quantification of the breadth of the niche, or testing and comparison of the breadths of the ecological niches of 2 species. The outlying mean index method (OMI analysis, Dolédec et al. 2000) allows a comparison of the relative position and the breadth of the species niche. This method is especially useful when a high number of species is compared. This technique assesses the relative position of the species by calculating a marginality index, which is represented by the distance between the mean habitat conditions of a species (sensu Hutchinson 1957) and the average habitat conditions of the sampled region. A tolerance index that evaluates the niche breadth and a residual tolerance index that informs on the variance of the species niche not considered in the marginality axis are also computed. The niche breadth index is a measure of intra-group variance weighted by the relative abundance of the species. Our breadth niche index is simply the mean Euclidean distance based on all abiotic variables, and the procedures that allow comparisons to be tested are distribution-free. As variables are most often measured in different units, the Euclidean distance has to be calculated on transformed data. We normalized the data so that each variable has a length of 1 . The Euclidean distance can be replaced by any type of distance as long as the conditions of application of the index are met (Legendre \& Legendre 1998). This represents a great advantage in addition to the simplicity of the technique.

The definition of the ecological niche used in this study is that of Hutchinson (1957). This also represents what is sometimes called the environmental niche as opposed to the trophic niche (see the discussion in Guisan \& Wilfried 2005). Hutchinson (1957) made the distinction between fundamental and realized niches, stating that the latter was smaller than the fundamental niche. Recently, however, Pulliam (2000) clearly demonstrated that when dispersal was high, the realized niche could be larger than the fundamental niche. Pulliam (2000) distinguished source habitats, where local reproduction is higher than local mortality, from sink habitats, where local mortality is superior to local reproduction. Dispersal in the marine pelagic domain of the North Atlantic Ocean is high as there is no physical barrier. This is probably why marine biogeographical regions are less well identified than in the terrestrial realm (Rapoport 1994). High dispersal in the marine pelagic environment is likely to increase the breadth of the niches for Calanus spp. This makes the realized niches of both Calanus spp. probably larger than their fundamental niches (Pulliam 2000). Therefore, their ecological niches can be overestimated. Furthermore, estimation of niche breadth of both species can possibly be biased by a difference in the dispersal rate between the 2 Calanus spp. Dispersal is expected to be higher for $C$. finmarchicus because this oceanic species is less limited by the bathymetric factor than its congeneric species (Beaugrand et al. 2002a). One way of overcoming this problem is to assess the ecological niche using a combination of physiological and environmental variables (Pulliam 2000). The present procedures could be restarted on the outputs of such a physiological model and the results compared. The difference between the niche assessed by this method and that based on in situ measurements would enable an assessment of the dispersal rate of both species and could lead to an estimation of the fundamental niches of both C. finmarchicus and C. helgolandicus.

The test can be sensitive if the number of occurrence points is too different between species. In such a case, a procedure of random selection of the occurrence points can help to prevent the bias related to the estimation of the probability. Other limitations are more dependent on the theory behind the concept of ecological niche, sampling strategy and coverage (Legendre \& Legendre 1998), spatial scale selection (Beaugrand \& Ibañez 2002) and other potential caveats discussed recently by Guisan \& Wilfried (2005). Spatial autocorrelation is an important issue in ecological niche modelling (Dormann et al. 2007). Spatial dependence or autocorrelation, related to biological or physical data, might increase the Type I error rate and lead to the incorrect rejection of the null hypothesis of no effect. In our study, data used in the test are derived from a mean abundance calculated for a given class interval using 3 variables (temperature, salinity and spatial variability in the bathymetry). Information on space is lost and the calculation of the average mixed observations located in very different places. This reduces the effect of spatial autocorrelation. We believe that the very low probabilities $(p<0.0001)$ found in this study make our conclusions robust. A special procedure of randomization could be implemented in the test to try to overcome this potential problem.

The procedures presented in this paper represent a simple and rapid way to quantify and compare the 
breadth of the ecological niche of 2 species and to test whether species niches are significantly different. We used a Euclidian distance in the present paper, but virtually any measure of distance can be used (e.g. Chord distance). Such a method could be extended to compare the ecological niches of more than 2 species by correcting the probabilities of each species pair for multiple test comparisons (Sokal \& Rohlf 1995). The procedure can also be reduced to the univariate case (i.e. a single environmental variable) to quantify the degree of tolerance of a species to a change in an environmental factor. The quantification of the degree of tolerance is often important in ecophysiological and global change related issues.

Acknowledgements. We are grateful to all past and present members and supporters of the Sir Alister Hardy Foundation for Ocean Science, whose continuous efforts have allowed the establishment and maintenance of the long-term CPR data set. The survey depends on the owners, masters and crews of the ships that tow the CPRs. The research was supported by the UK Department for Environment, Food and Rural Affairs (DEFRA), and the European Network of Excellence EUROCEANS.

\section{LITERATURE CITED}

Austin MP (2002) Spatial prediction of species distribution: an interface between ecological theory and statistical modelling. Ecol Model 157:101-118

Austin MP, Belbin L, Meyers JA, Doherty MD, Luoto M (2006) Evaluation of statistical models used for predicting plant species distributions: role of artificial data and theory. Ecol Model 199:197-216

Batten SD, Clark R, Flinkman J, Hays G and others (2003) CPR sampling: the technical background, materials, and methods, consistency and comparability. Prog Oceanogr 58:193-215

Beaugrand G (2003) Long-term changes in copepod abundance and diversity in the north-east Atlantic in relation to fluctuations in the hydro-climatic environment. Fish Oceanogr 12:270-283

Beaugrand G (2004a) Continuous plankton records: plankton atlas of the North Atlantic Ocean (1958-1999). I. Introduction and methodology. Mar Ecol Prog Ser Suppl 2004:3-10

Beaugrand G (2004b) The North Sea regime shift: evidence, causes, mechanisms and consequences. Prog Oceanogr 60:245-262

Beaugrand G, Ibañez F (2002) Spatial dependence of pelagic diversity in the North Atlantic Ocean. Mar Ecol Prog Ser 232:197-211

Beaugrand G, Reid PC (2003) Long-term changes in phytoplankton, zooplankton and salmon linked to climate change. Glob Change Biol 9:801-817

Beaugrand G, Ibañez F, Lindley JA, Reid PC (2002a) Diversity of calanoid copepods in the North Atlantic and adjacent seas: species associations and biogeography. Mar Ecol Prog Ser 232:179-195

Beaugrand G, Reid PC, Ibañez F, Lindley JA, Edwards M (2002b) Reorganisation of North Atlantic marine copepod biodiversity and climate. Science 296:1692-1694

Beaugrand G, Brander KM, Lindley JA, Souissi S, Reid PC (2003) Plankton effect on cod recruitment in the North Sea. Nature 426:661-664
Berry KJ, Mielke PW (1983) Computation of finite population parameters and approximate probability values for multiresponse permutation procedures (MRPP). Commun Stat B Simul 12:83-107

Berry PM, Dawson TP, Harrison PA, Pearson RG (2002) Modelling potential impacts of climate change on the bioclimatic envelope of species in Britain and Ireland. Glob Ecol Biogeogr 11:453-462

Bonnet D, Richardson AJ, Harris R, Hirst AG and others (2005) An overview of Calanus helgolandicus ecology in European waters. Prog Oceanogr 65:1-53

Colwell RK, Hurtt GC (1994) Nonbiological gradients in species richness and a spurious Rapoport effect. Am Nat 144: 570-595

Cornelius JM, Reynolds JF (1991) On determining the statistical significance of discontinuities within ordered ecological data. Ecology 72:2057-2070

Dolédec S, Chessel D, Gimaret-Carpentier C (2000) Niche separation in community analysis: a new method. Ecology 81:2914-2927

> Dormann CF, McPherson JM, Araujo MB, Bivand R and others (2007) Methods to account for spatial autocorrelation in the analysis of species distributional data: a review. Ecography 30:609-628

> Elith J, Graham CH, Anderson RP, Dudik M and others (2006) Novel methods improve prediction of species distributions from occurence data. Ecography 29:129-151

Elton C (1927) Animal ecology. Sidgwick \& Jackson, London

Grinnell J (1917) The niche-relations of the California thrasher. Auk 34:427-433

Guisan A, Wilfried T (2005) Predicting species distribution: offering more than simple habitat models. Ecol Lett 8: 993-1009

Guisan A, Zimmermann NE (2000) Predictive habitat distribution models in ecology. Ecol Model 135:147-186

> Harmon LJ, Kolbe JJ, Cheverud JM, Losos JB (2005) Convergence and the multidimensional niche. Evolution 59: 409-421

Hastie TJ, Tibshirani RJ (1990) Generalized additive models. Chapman \& Hall, London

$>$ Heegaard E (2002) The outer border and central border for species-environmental relationships estimated by nonparametric generalised additive models. Ecol Model 157: 131-139

> Helaouët P, Beaugrand G (2007) Macroecological study of the niche of Calanus finmarchicus and C. helgolandicus in the North Atlantic Ocean and adjacent seas. Mar Ecol Prog Ser 345:147-165

Hölzel N (2003) Re-assessing the ecology of rare floodmeadow violets (Viola elatior, V. pumila and V. persicifolia) with large phytosociological data sets. Folia Geobot 38:281-298

Hutchinson GE (1957) Concluding remarks. Cold Spring Harbor Symp Quant Biol 22:415-427

Jackson DA, Somers KM (1989) Are probability estimates from the permutation model of Mantel's test stable? Can J Zool 67:766-769

Jackson JBC, Kirby MX, Berger WH, Bjorndal KA and others (2001) Historical overfishing and the recent collapse of coastal ecosystems. Science 293:629-638

Lacoste A, Salanon R (2001) Eléments de biogéographie et d'écologie. Nathan/HER, Paris

Leathwick JR, Austin MP (2001) Competitive interactions between tree species in New Zealand's old-growth indigenous forests. Ecology 82:2560-2573

> Leathwick JR, Elith J, Hastie T (2006) Comparative performance of generalized additive models and multivariate 
adaptive regression splines for statistical modelling of species distributions. Ecol Model 199:188-196

Legendre P, Legendre L (1998) Numerical ecology. Elsevier Science BV, Amsterdam

Longhurst A (1998) Ecological geography of the sea. Academic Press, London

Lyons SK, Willig MR (1997) Latitudinal patterns of range size: methodological concerns and empirical evaluations for New World bats and marsupials. Oikos 79:568-580

Manel S, Dias JM, Ormerod SJ (1999) Comparing discriminant analysis, neural networks and logistic regression for predicting species distributions: a case study with a Himalyan river bird. Ecol Model 120:337-347

Mauchline J (1998) The biology of calanoid copepods. Academic Press, San Diego, CA

McCullagh P, Nelder JA (1983) Generalized linear models. Chapman \& Hall, London

Mielke PW, Berry KJ, Brier GW (1981) Application of multiresponse permutation procedures for examining seasonal changes in monthly mean sea-level pressure patterns. Mon Weather Rev 109:120-126

Pearson DL (1994) Selecting indicator taxa for the quantitative assessment of biodiversity. Philos Trans R Soc Lond B Biol Sci 345:75-79

Planque B (1996) Spatial and temporal fluctuations in Calanus populations sampled by the Continuous Plankton Recorder. $\mathrm{PhD}$ thesis, University of Pierre et Marie Curie, Paris VI

Pulliam R (2000) On the relationship between niche and distribution. Ecol Lett 3:349-361

Rapoport EH (1994) Remarks on marine and continental biogeography: an areographical viewpoint. Philos Trans R Soc Lond B Biol Sci 343:71-78

Reid P, Edwards M (2001a) Plankton and climate. In: Steele J (ed) Encyclopaedia of sciences. Academic Press, Oxford, p 2194-2200

Reid PC, Edwards M (2001b) Long-term changes in the pelagos, benthos and fisheries of the North Sea. Senckenb Marit 32:107-115

Reid PC, Colebrook JM, Matthews JBL, Aiken J and others (2003) The Continuous Plankton Recorder: concepts and history, from plankton indicator to undulating recorders. Prog Oceanogr 58:117-173

Editorial responsibility: Otto Kinne, Oldendorf/Luhe, Germany
Rohde K, Heap M, Heap D (1993) Rapoport's rule does not apply to marine teleosts and cannot explain latitudinal gradients in species richness. Am Nat 142:1-16

Rosenzweig ML (1995) Species diversity in space and time. Cambridge University Press, Cambridge

Sanchez-Cordero V, Cirelli V, Munguia M, Sarkar S (2005) Place prioritization for biodiversity representation using species' ecological niche modeling. Biodiversity Informatics 2:11-23

Sanders NJ (2002) Elevational gradients in ant species richness: area, geometry, and Rapoport's rule. Ecography 25: 25-32

Sokal RR, Rohlf FJ (1995) Biometry. WH Freeman \& Company, New York

Speirs DC, Gurney WSC, Heath MR, Wood SN (2005) Modelling the basin-scale demography of Calanus finmarchicus in the north-east Atlantic. Fish Oceanogr 14:333-358

Stevens GS (1989) The latitudinal gradient in geographic range: how so many species coexist in the tropics. Am Nat 133:240-256

Stewart KM, Bowyer RT, Kie JG, Dick BL, Ben-David M (2003) Niche partitioning among mule deer, elk, and cattle: Do stable isotopes reflect dietary niche? Ecoscience 10: 297-302

ter Braak CJF (1987) Ordination. In: Jongman RHG, ter Braak CJF, van Tongeren OFR (eds) Data analysis in community and landscape ecology. Pudoc, Wageningen, p 91-173

ter Braak CJF, Looman CWN (1987) Regression. In: Jongman RHG, ter Braak CJF, van Tongeren OFR (eds) Data analysis in community and landscape ecology. Pudoc, Wageningen, p $27-77$

Warner AJ, Hays GC (1994) Sampling by the Continuous Plankton Recorder survey. Prog Oceanogr 34:237-256

Webster R (1973) Automatic soil-boundary location from transect data. J Int Assoc Math Geol 5:27-37

- Woodruff S, Slutz R, Jenne R, Steurer P (1987) A comprehensive ocean-atmosphere dataset. Bull Am Meteorol Soc 68:1239-1250

Zimmerman GM, Goetz H, Mielke PW (1985) Use of an improved statistical method for group comparisons to study effects of prairie fire. Ecology 66:606-611

Submitted: February 22, 2007; Accepted: January 14, 2008 Proofs received from author(s): June 25, 2008 